\title{
33679000626012
}

BNWL - 1950 PT 4

UC -48

PACIFIC NORTHWEST LABORATORY

ANNUAL REPORT FOR 1974

TO THE

USAEC DIVISION OF BIOMEDICAL AND ENVIRONMENTAL RESEARCH

PART 4 PHYSICAL AND ANALYTICAL SCIENCES

By

J. M. Nielsen

with Major Contributions from

Staff Members of

Radiological Sciences Department

Physics and Instrumentation Department

February 1975

On January 19, 1975, research and development programs of the U.S. Atomic Energy Commission (AEC) became part of the newly formed Energy Research and Development Administration (ERDA). In this report, since it refers to work done in 1974, most references are to AEC programs. 


\section{- POPULATION RADIATION EXPOSURE}

The objective of this project is to develop comprehensive estimates of the radiation dose to the population that would result from successful development and routine use of $\mathrm{Pu}-238$ fueled artificial hearts.

The REPRIEVE computer program designed to carry out the ca1culations and summations necessary to identify the population dose by detailed classifications of heart device recipients and radiation exposure subjects was completed.

The basis for projecting future heart disease death rates was revised and the "best estimate" projection now tracks statistical data remarkably well. A series of REPRIEVE cases were prepared that covered the range of uncertainties in future artificial heart use. Population doses were substantially less than the preliminary estimates reported in the 1973 annual report. Total population dose estimates range from 60,000 to $500,000 \mathrm{rem} / \mathrm{yr}$ in the year 2000 .

Population Radiation Exposure R. W. MCKee and L. I. Clark

Successful development and routine use of $\mathrm{Pu}-238$ fueled artificial heart devices would expose persons in the vicinity of these devices to small amounts of radiation. The objective of this study is to develop comprehensive estimates of these low-level radiation doses so that the physiological implications to others than the device users can be evaluated.

The method used in this study to develop the estimates was to subdivide the potential artificial heart population into smal1 identifiable groups whose daily activities could be identified employing sample survey techniques. Dose calculations for all of the activities were summed up for all user groups to estimate the population dose. Essential components of the study include: 1) projections of potential artificial heart users by age, sex, household characteristics, etc., 2) surveys to develop time-distance relationships of potential recipients with others, 3) calculations of radiation dose factors, and 4) development of a computer program to sum up and classify the population dose.

During 1974 the REPRIEVE computer program expansion was completed, dose rate calculations were revised, new. projections of heart disease death rates were developed and a series of REPRIEVE cases were prepared that encompass the range of uncertainty in the principal parameters of the population dose estimates. An analysis of potential population dose from $\mathrm{Pu}-238$ powered cardiac pacemakers was also prepared and a report published. ${ }^{4}$

The REPRIEVE computer program was revised to provide a more comprehensive dose estimate and a detailed breakdown of the population dose. 
The calculation requires 23,000 input items and the final population dose matrix includes 240,000 components. The population dose can be identified in terms of age, sex and relationship to the device recipients; age, sex and household. type of the recipient and by major activity classifications. However, a portion of the dose (about $35 \%$ ) cannot be identified other than to the general populace.

The dose versus distance relationships were recalculated using an improved version of the QADP5A computer code. This resulted in significantly lower dose rates than previous calculations. The calculations showed good agreement with phantom experiments.

One of the important parameters affecting potential demand for an artificial heart is the future incidence of fatal heart disease. From an analysis of statistical data for other fatal diseases now under control, a learning curve relationship had previously been derived that appears to predict fatality incidence. Use of the relationship requires identification of a peak in death rate statistics. Recent data pointed up some inconsistencies in the previous application of the relationship to fatal heart disease and the analysis was redone based primarily on ischemic (formerly arteriosclerotic)

heart disease. The agreement between the resulting projection and the available statistical data is remarkable. For example, starting with the 1965 death rate for total heart dis ease, an age-adjusted ( 1940 basis) death rate of 242 deaths/100,000 was projected for 1973 compared to 243 deaths $/ 100,000$ obtained from provisional vital statistics.

In addition to the above "best estimate" projection of fatal heart disease incidence, both a maximum and minimum incidence were projected. The maximum projection assumes that crude heart disease death rates will remain at the average rate since 1965 . (The trend appears clearly downward, however.) The minimum projection assumes that heart disease will de- cline at a rate characterized by other fatal diseases now controlled (this is a quite optimistic assumption).

Combining these projections with estimates of eligible candidates, death rates and device failure rates, and assuming general use could begin in 1985 , the estimates of potential artificial heart use shown in Figure 5.6 were developed. The number of devices in use and population dose estimates for the year 2000 are shown in Table 5.3. A typical distribution of the dose is shown in Table 5.4. other cases have also been calculated taking into account uncertainty ranges in eligible candidates, death rates after implant and device failure rates. These expand the range of population dose estimates in the year 2000 to 60,000 to $500,000 \mathrm{rem} / \mathrm{yr}$. $\mathrm{Re}-$ sults will be published in a topical report in preparation at year end.

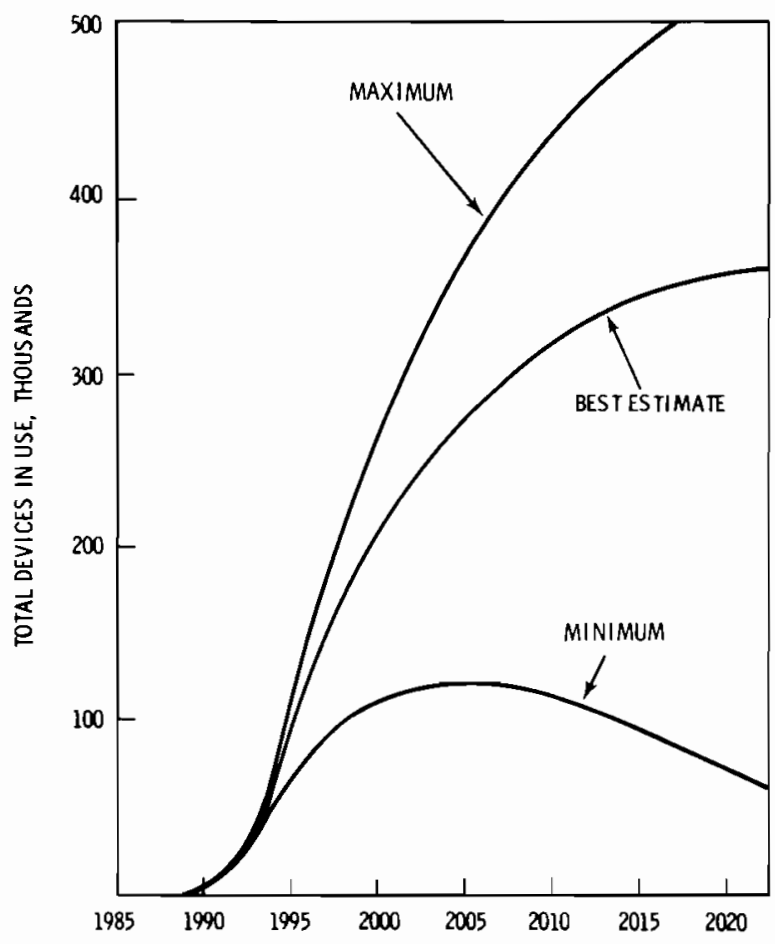

FIGURE 5.6. Estimates of Potential Artificial Heart Use. 


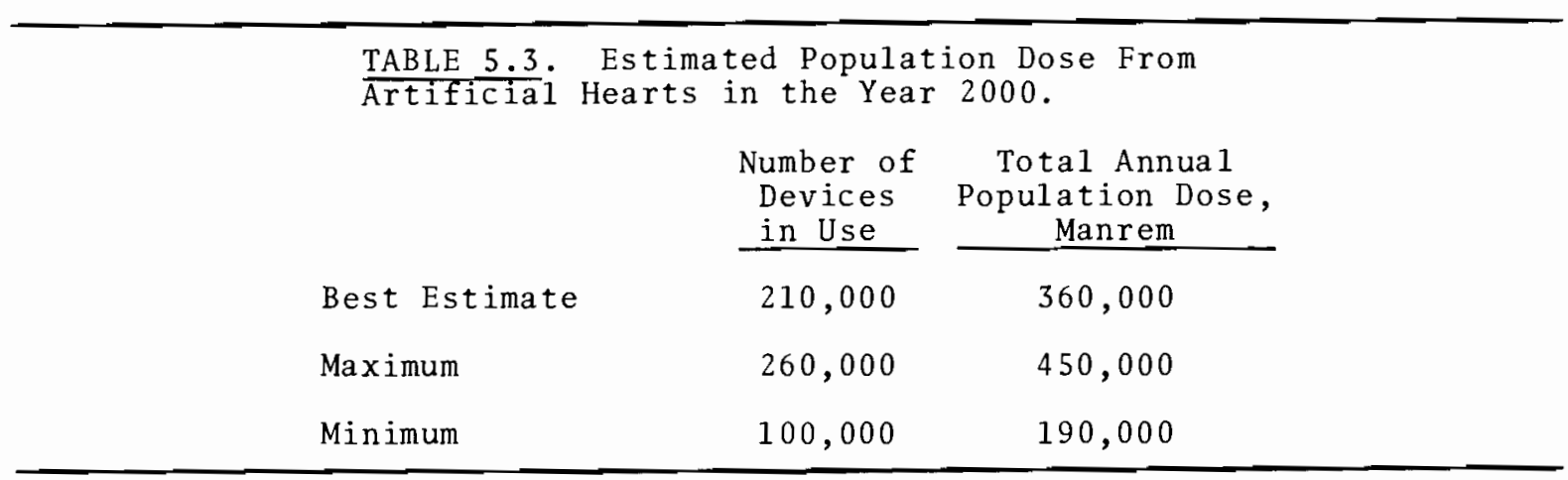

TABLE 5.4. Distribution of Population Dose.

\begin{tabular}{cc}
$\begin{array}{c}\text { Percent of } \\
\text { Population } \\
\text { Dose }\end{array}$ & $\begin{array}{c}\text { Average Dose } \\
\text { Per Person } \\
\text { rem/yr }\end{array}$ \\
\hline
\end{tabular}

Spouses

$\begin{array}{lll}\text { Under Age } 50 & 10 & 0.9 \\ \text { Age } 50 \text { and Over } & 25 & 0.8\end{array}$

Other Household Members

\begin{tabular}{|c|c|c|}
\hline Age $\quad 0-17$ & 6 & 0.2 \\
\hline $18-49$ & 3 & 0.2 \\
\hline $50+$ & 1 & 0.2 \\
\hline n-Work Associates & 9 & 0.007 \\
\hline rk Associates & 11 & 0.02 \\
\hline neral Populace & 35 & 0.0003 to \\
\hline & & 0.0006 \\
\hline
\end{tabular}

\section{REFERENCES}

1. E. T. Merri11, AlthaEA: A OneDimensiona 1 Two-Group Diffusion Code with an Effective Four-Group Burnup, BNWL-462, Pacific Northwest Laboratory, Richland, WA, May 1971.

2. M. J. Bel1, ORIGEN - The ORNL ISOtope Generation and Depletion Code, ORNL-4628, O?k Ridge, TN, May 1973.
3. Curium-244/Neptunium-237 Recovery from the Barnwel1 Nuclear Fuel Plant, Final Briefing, General Atomic Company, San Diego, CA, June 1974 .

4. R. W. McKee, L. L. C1ark, B. M. Cole and R. A. Libby, Dose-tothe-Population Estimates for Use of Radioisotope Powered Cardiac pacemakers, BNWL-1858, Bat te1leNorthwest, Richland, WA., September 1974 . 


\section{PUBL ICATION}

Cross, F. T., Dose Rates to a Bystander from an Artificial Heart Power Source, BNWL-SA-52 51 , Battelle-Northwest, Richland, WA, 1974. 